\title{
Optimization of the basophil activation test in the diagnosis and qualification for treatment by means of allergen-specific immunotherapy in children with respiratory allergy to house dust mites
}

\author{
Radoslaw Spiewak', Aleksandra Gregorius ${ }^{*}$, Ewa Czarnobilska² \\ From EAACI Skin Allergy Meeting 2014 \\ Krakow, Poland. 18-20 September 2014
}

Diagnosis of diseases, especially qualification for treatment should be based on the methods properly optimized in order to minimize the risk of incorrect qualification to unnecessary treatments, or neglecting treatment wherever it is needed. Among possible alternatives for routine allergy diagnostic tests, hopeful mentions can be found of the basophil activation test (BAT), which replicates in vitro reactions that occur in the body during basophil response to allergens, thus giving a chance for forecasting the severity of allergic reaction.

\section{Aim}

The aim of the study was to optimize the basophil activation test in the detection of house dust mite allergy in Polish children with allergic respiratory diseases.

\section{Patients and methods}

The study involved 32 patients, with symptoms of asthma or allergic rhinitis, qualified for sIT with the $D$ pteronyssinus allergen by an experienced pediatric allergist. The control group consisted of an equal number of sex- and agematched children with the same clinical diagnoses, yet sensitized to allergens other than D. pteronyssinus. In all patients, the BAT test was performed with five dilutions of D. pteronyssinus allergen. In order to detect possible cross-reactivity, BAT was also carried out with one dilution of $D$. farinae. The results were analyzed by the means of ROC.

\section{Results}

The highest diagnostic efficiency in the analyzed population was yielded by the cut-off of $9.76 \%$ of activated basophils after activation with a single allergen concentration of $2.25 \mathrm{ng} / \mathrm{ml}$ (sensitivity 90,63\%, specificity 100\%). The computed value differed significantly from the cut-off value of $15 \%$ proposed by the manufacturer of the test. Qualification of the patients with the use of the proposed protocol and cut-off value did not differ from the "gold standard", i.e. qualification by the physician, while adoption of the parameters proposed by the manufacturer would result in a significant difference in this regard.

\section{Conclusions}

BAT is a useful method in the diagnosis and qualification of children with asthma and allergic rhinitis for the allergen-specific immunotherapy with house dust mite allergens. Optimal cut-off values for the test differ from those proposed by the manufacturer of the reagents. Facing the risk of incorrect qualification of patients for costly, longlasting and potentially risky allergen-specific immunotherapy, incurring the cost of basophil activation test seems justified, especially in the case of diagnostic doubts.

\footnotetext{
Authors' details

'Jagiellonian University Medical College Faculty of Pharmacy, Dept of Experimental Dermatology and Cosmetology, Krakow; Poland. ${ }^{2}$ Jagiellonian University Medical College Faculty of Pharmacy, Department of Toxicology and Environmental Disease, Krakow, Poland.
} 
doi:10.1186/2045-7022-5-S1-P10

Cite this article as: Spiewak et al:: Optimization of the basophil activation test in the diagnosis and qualification for treatment by means of allergenspecific immunotherapy in children with respiratory allergy to house dust mites. Clinical and Translational Allergy 2015 5(Suppl 1):P10.

Submit your next manuscript to BioMed Central and take full advantage of:

- Convenient online submission

- Thorough peer review

- No space constraints or color figure charges

- Immediate publication on acceptance

- Inclusion in PubMed, CAS, Scopus and Google Scholar

- Research which is freely available for redistribution

Submit your manuscript at www.biomedcentral.com/submit
C Biomed Central 